\title{
DETALHAMENTO \\ FONÉTICO-ACÚSTICO \\ DAS SÍLABAS CCV \\ NA FALA INFANTIL \\ TÍPICA E COM DESVIO \\ FONOLÓGICO
}

\section{DETALLES FONÉTICO-ACÚSTICOS DE LAS SÍLABAS CCV EN EL HABLA INFANTIL TÍPICA Y CON DESVIACIÓN FONOLÓGICA}

PHONETIC-ACOUSTIC DETAILING OF CCV SYLABLES IN TYPICAL CHILDREN'S SPEECH AND WITH PHONOLOGICAL DISORDER

Aline Mara de Oliveira*

Universidade Federal de Santa Catarina

Izabel Christine Seara ${ }^{* *}$

Universidade Federal de Santa Catarina

Ronaldo Mangueira Lima Jr***

Universidade Federal do Ceará

RESUMO: Este estudo experimental objetivou a caracterização fonético-acústica de encontros consonantais em sílabas CCV. Participaram do estudo crianças entre 5 e 6 anos com fala típica e com desvio fonológico. Os resultados mostraram que os dois grupos estão em processo de refinamento articulatório dos gestos envolvidos na produção das sílabas CCV, apresentando os

\footnotetext{
* Doutora em Estudos Linguísticos pela Universidade Estadual Paulista. Professora Adjunto da Universidade Federal de SantaCatarina, Centrode Ciências da Saúde, Departamentode Fonoaudiologia. E-mail:aline.mara.oliveira@ufsc.br.

** Doutora em Linguística pela Universidade Federal de Santa Catarina. Professora Titular da Universidade Federal de Santa Catarina, Centro de Comunicação e Expressão, Departamento de Língua e Literatura Vernáculas, Conselho Nacional de Desenvolvimento Científico e Tecnológico (CNPq), processo n. $308066 / 2018-9$. E-mail: izabel.seara@ufsc.br

*** Doutor em Linguística pela Universidade de Brasília. Professor Adjunto da Universidade Federal do Ceará, Centro de Humanidades, Departamento de Estudos da Língua Inglesa, suas Literaturas e Tradução. E-mail: ronaldojr@letras.ufc.br.
} 
mesmos eventos acústicos que caracterizam tal refinamento, como desvozeamento, bloqueios orais e múltiplos bursts. No entanto, as crianças com desvio fonológico apresentaram esses eventos acústicos com maior ocorrência. Para esse grupo, foi constatado ainda que o rótico em sílabas CCV não foi produzido, no entanto, o VOT e as vogais núcleo apresentaram duração mais longa quando comparada à duração exibida nos dados do grupo de fala típica. Essas características parecem evidenciar que as crianças de fala atípica têm conhecimento fonológico quanto à presença de um segmento que ainda não é produzido por elas.

PALAVRAS-CHAVE: Fala infantil atípica. Fala infantil típica. Encontros consonantais. Estudo fonético-acústico.

RESUMEN: Este estudio experimental tuvo como objetivo la caracterización fonética y acústica de los encuentros consonánticos en sílabas CCV. Participaron en el estudio niños de entre 5 y 6 años con habla típica y con desviación fonológica. Los resultados demuestran que ambos grupos están en el proceso de perfeccionamiento articulatorio de los gestos involucrados en la producción de las sílabas CCV, presentando los mismos eventos acústicos que caracterizan esta mejora, como ensordecimiento, bloqueos orales y múltiples bursts. Sin embargo, los niños con desviación fonológica presentaron estos eventos acústicos con mayor frecuencia. Para ese grupo, también se constató que el rotico en sílabas CCV no se produjo; sin embargo, el VOT y las vocales núcleo tuvieron una duración más larga en comparación con la duración que se muestra en los datos del grupo de habla típica. Esas características parecen demostrar que los niños de habla atípica tienen conocimiento fonológico en relación con la presencia de un segmento que todavía no producen.

PALABRAS CLAVE: Habla infantil atípica. Habla infantil típica. Agrupaciones consonánticas. Estudio de fonética y acústica.

ABSTRACT: This experimental study aimed at the phonetic-acoustic characterization of consonant clusters in CCV syllables. Children between 5 and 6 years old with typical speech and phonological disorders participated in the study. The results showed that the two groups are in the process of articulatory fine-tuning of the gestures involved in the production of CCV syllables, presenting the same acoustic events that characterize such refinement, such as devoicing, oral interruptions and multiple bursts. However, children with phonological disorders presented these acoustic events with greater frequency. For this group, we also found that the rhotic sound in CCV syllables was not produced; however, the VOT and the nuclear vowel had a longer duration when compared to the duration in the data of the typical speech group. These characteristics seem to show that children with atypical speech have phonological knowledge of the presence of a segment that is not yet produced by them.

KEYWORDS: Atypical children's speech. Typical children's speech. Consonantal clusters. Phonetic-acoustic study.

\section{INTRODUÇÃO}

Este estudo tem por objetivo caracterizar acusticamente a produção de sílabas CCV, cuja segunda consoante seja um tepe, produzidas por crianças brasileiras entre 5 e 6 anos de idade com fala típica e com desvio fonológico (fala atípica). Pesquisas (SILVEIRA, 2007; NISHIDA, 2009, BELANDO et al., 2018, por exemplo) sobre encontros consonantais tautossilábicos, isto é, encontros consonantais na mesma sílaba, como aqueles presentes em estruturas silábicas CCV, têm reportado a presença de um elemento vocálico quando o tepe é produzido como segunda consoante. Nesse caso, as sílabas CCV do português brasileiro (doravante PB) são constituídas de plosivas ou fricativas + tepe.

Na literatura, encontramos estudos acústicos referentes à produção de sílabas CCV, como Nishida (2009), que, investigando as sílabas do PB constituídas de plosivas + tepe + vogal, produzidas por adultos brasileiros, identificou um elemento vocálico entre as consoantes plosivas e o tepe. Para esse autor, a estrutura de formantes do elemento vocálico que antecede o tepe é semelhante à qualidade da vogal nuclear da sílaba CCV. Esse fato permite dizer que a vogal núcleo ${ }^{1}$ é entrecortada pelo tepe. Silveira (2007), também analisando acusticamente esses encontros consonantais, detectou a presença de um elemento vocálico, no entanto, com qualidade acústica significativamente diferente das vogais núcleo correspondentes.

Ainda com relação às consoantes oclusivas que constituem as sílabas CCV, Cristofolini (2013) trata da produção dessas consoantes e de especificidades acústicas encontradas na fala de crianças de 6 a 12 anos de idade, que remetem a um refinamento articulatório

\footnotetext{
${ }^{1}$ No presente estudo, denominamos a vogal que ocupa o núcleo das sílabas CCV e CV de vogal núcleo, conforme Silveira (2007).
} 
ao longo dos anos. Nesse estudo, a autora indicou que, após a aquisição fonológica, ocorre um período de refinamento dos gestos articulatórios envolvidos na produção de fala. Como nossos sujeitos de pesquisa têm idades entre 5 e 6 anos, observaremos também eventos acústicos que possam caracterizar diferentes evoluções em relação a esse período de refinamento articulatório de crianças com fala típica e com desvio fonológico.

Portanto, no presente estudo, considerando que, conforme aponta Cristofolini (2013), a criança, depois do período de aquisição fonológica, ainda esteja em processo de refinamento articulatório dos gestos envolvidos na produção das consoantes plosivas e fricativas, buscamos verificar, a partir de análises qualitativa e quantitativa, se as consoantes que constituem as sílabas CCV, produzidas por crianças entre 5 e 6 anos com fala típica e atípica, apresentam características acústicas que indiquem que os dois grupos estejam em processo de refinamento articulatório. Para isso, procuraremos também características desse refinamento articulatório em função das particularidades que definem os dois grupos de crianças estudados.

Ao investigar a duração de sílabas CCV e CV em crianças com desenvolvimento típico de linguagem e em crianças com desvio fonológico, Vassoler (2016) identificou valores de duração absoluta e relativa que, independente da condição clínica da criança, foram maiores nas sílabas CCV se comparadas às sílabas CV. Entretanto, ao comparar a duração das sílabas CCV produzidas pelas crianças típicas com crianças com desvio fonológico, não houve diferença estatisticamente significativa. Por esse fato, faremos uma análise detalhada das consoantes e vogais que constituem as sílabas CCV, produzidas pelos dois grupos de crianças, para verificar se há diferenças entre o grupo de fala típica e atípica.

Desse modo, nesta análise, a partir dos resultados de Vassoler (2016), observaremos dados relacionados à duração do VOT em sílabas iniciadas por oclusivas e da vogal núcleo das sílabas CCV e CV que serão comparados entre os dois grupos de crianças, verificando diferenças que sejam estatisticamente relevantes. Os resultados certamente complementarão os achados desses estudos anteriores (OLIVEIRA; BERTI, 2018; VASSOLER, 2016; CRISTOFOLINI, 2013), apontando os elementos que podem trazer diferenças para os grupos em investigação neste estudo. Verificaremos também a presença ou ausência acústica do elemento vocálico que antecede o tepe; e a duração e frequência dos formantes desse elemento vocálico e da vogal núcleo produzidas pelas crianças que apresentarem o tepe nas sílabas CCV. Além disso, identificaremos os demais tipos de róticos produzidos pelas crianças e os eventos acústicos que não sejam comuns na fala adulta.

Considerando esta análise acústica detalhada dos dados, pretendemos com este estudo responder às seguintes questões de pesquisa:

(1) Qual é o comportamento acústico de consoantes CCV na fala típica e atípica, observando a produção do rótico, o vozeamento/desvozeamento de consoantes vozeadas, a produção da vogal de apoio e da vogal núcleo e a duração do VOT?

(2) Que diferenças podem ser constatadas considerando a evolução do refinamento articulatório encontrado na fala típica e na fala atípica?

Para alcançar os objetivos pretendidos e responder às questões de pesquisa anteriormente colocadas, este texto apresentará na sequência uma revisão de literatura, tratando de pesquisas concernentes à produção de sílabas CCV e dos elementos vocálicos e consonantais que compõem tais sílabas. Em seguida, serão descritos os procedimentos metodológicos empregados no presente estudo e os resultados obtidos. Após essa etapa, apresentaremos as respostas às questões de pesquisa e nossas considerações finais.

\section{CARACTERÍSTICAS ACÚSTICO-ARTICULATÓRIAS DE SÍLABAS CCV}

Como iremos analisar detalhadamente os dados produzidos por dois grupos de crianças, primeiramente concernentes às sílabas CCV, constituídas de consoante+rótico+vogal, faremos inicialmente uma revisão de estudos que tratam de onsets complexos, como os aqui investigados, tanto na fala adulta quanto na fala infantil.

A ocorrência de um elemento vocálico entre as consoantes e o tepe, em sílabas com encontros consonantais tautossilábicos (CCV), foi identificada em vários estudos (CAGLIARI, 2002; SILVEIRA, 2007; SILVEIRA; SEARA, 2008; NISHIDA, 2009). O elemento 
vocálico pode ser denominado como abertura oral (SILVA, 1996); elemento vocálico (NISHIDA, 2009) ou vogal de apoio (SILVEIRA, 2007), podendo surgir nas estruturas silábicas do tipo $C_{1} C_{2} V$ ou $C_{1} V C_{2}$, quando $C_{2}$ é o tepe. Esses autores verificaram também que o tepe apresenta, articulatoriamente, uma oclusão bastante breve (quando comparada à oclusão presente nas consoantes oclusivas) (CLARK; YALLOP, 1995; SILVA, 1996; SILVEIRA, 2007). Acusticamente, observa-se uma região de muito baixa energia (devido ao rápido fechamento da oclusão oral), que é representada em um espectrograma por "um espaço praticamente vazio" (SILVA, 1996, p. 18). Observe, na Figura 1, um exemplo de produção de um tepe:

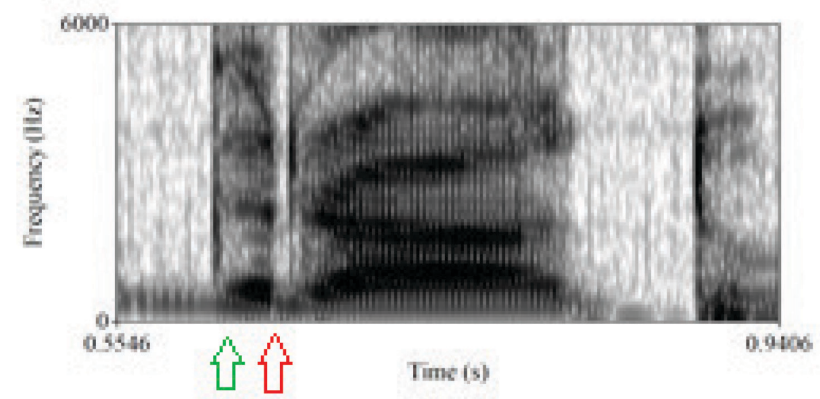

Figura 1: Espectrograma de um exemplo de produção de um tepe na palavra grato (fala infantil).

Fonte: elaboração dos autores

Na Figura 1, podem ser observados os eventos acústicos que caracterizam a produção de um tepe: a vogal de apoio (seta verde) e a região de baixa intensidade (seta vermelha). Como esse elemento vocálico ocorre para "apoiar" o tepe, uma vez que no PB não é possível ocorrer dois sons de natureza descontínua lado a lado, a produção desse elemento faz com que o tepe sempre ocupe uma posição intervocálica (SILVA, 1996). O tepe é caracterizado por apresentar descontinuidade espectral (isto é, quando a ponta da língua toca a região alveolar, há uma breve interrupção da passagem do ar pelo trato vocal), irregularidade acústica² e baixa amplitude na forma de onda. Trata-se, portanto, de um som muito breve e descontínuo (NISHIDA, 2009).

As sílabas constituídas por obstruintes + vogal (CCV) no PB são compostas de plosivas ou fricativas + vogal de apoio + tepe + vogal núcleo. A produção desse elemento vocálico que antecede o tepe, no entanto, não é um fenômeno exclusivo do PB, visto que ocorre em outras línguas, como no irlandês moderno e no espanhol (SILVEIRA, 2007). Os valores obtidos pelos dois primeiros formantes (F1 e F2) dessa vogal de apoio variam de uma língua para outra (CRISTÓFARO-SILVA; ALMEIDA, 2008).

No que se refere ao $\mathrm{PB}$, não se conhecia a natureza do evento que ocorria entre a obstruinte e o tepe, a não ser que se assemelhava a uma vogal. Estudos sobre o rótico em encontros consonantais tautossilábicos, como o de Silva (1996), a partir de um detalhamento acústico de consoantes líquidas, verificou que o tepe, presente no onset de sílabas CCV, sempre se apoia em duas vogais. Pesquisas ainda indicam que a vogal anterior ao tepe e a vogal núcleo da sílaba CCV que segue o tepe apresentam diferenças em duração, porém frequências de ressonância semelhantes (SILVA, 1996; NISHIDA, 2009). Silveira (2007), também tratando de encontros tautossilábicos, apontou, no entanto, para elementos vocálicos distintos. Silveira e Seara (2008) observaram que a qualidade acústica da vogal de apoio difere da vogal núcleo correspondente, tanto em altura quanto em anterioridade/posterioridade. Assim, as autoras apuraram que a vogal de apoio que antecede uma vogal núcleo anterior alta também se apresenta como anterior alta, só que significativamente ${ }^{3}$ menos alta e menos anterior do que a vogal núcleo. A vogal de apoio que antecede a vogal núcleo baixa é antecedida por uma vogal de apoio significativamente menos baixa. Entretanto, a vogal de apoio que antecede uma vogal núcleo posterior alta apresenta altura e anterioridade semelhantes à da vogal núcleo. Observe, na Tabela 1, adaptada de Silveira e Seara

\footnotetext{
${ }^{2}$ Essa irregularidade acústica é vista como "[...] uma irregularidade de energia de produção que se revela na forma da onda, como a porção em que os períodos são Irregulares e sua amplitude quase atinge zero (durante o início do fechamento), para depois voltar a ter um valor mais alto (durante o final do fechamento)” (SILVA, 1996, p. 67)
}

${ }^{3}$ Para observação das diferenças entre as médias dos formantes das vogais núcleo e de apoio, foi usado o teste t e os resultados mostraram valores de $p<0,001$. Foi analisado um total de 480 dados. 
(2008), os valores obtidos para F1 (altura vocálica) e F2 (anterioridade-posterioridade vocálica) em palavras isoladas e em contexto de oclusivas, foco de nosso estudo, para ambos os sexos:

\begin{tabular}{|c|c|c|c|c|c|c|}
\hline \multirow{3}{*}{$\begin{array}{c}\text { Vogais } \\
\text { Formantes }\end{array}$} & \multicolumn{6}{|c|}{ Masculino } \\
\hline & \multicolumn{2}{|c|}{ [i] } & \multicolumn{2}{|c|}{ [a] } & \multicolumn{2}{|c|}{$[\mathbf{u}]$} \\
\hline & F1 & F2 & F1 & F2 & F1 & F2 \\
\hline VA & 369 & 1748 & 534 & 1387 & 370 & 1193 \\
\hline \multirow[t]{2}{*}{ VN } & 292 & 2149 & 733 & 1432 & 347 & 1053 \\
\hline & \multicolumn{6}{|c|}{ Feminino } \\
\hline Vogais & \multicolumn{2}{|c|}{$[\mathrm{i}]$} & \multicolumn{2}{|c|}{$[\mathrm{a}]$} & \multicolumn{2}{|c|}{$[\mathbf{u}]$} \\
\hline Formantes & F1 & F2 & F1 & $\mathrm{F} 2$ & F1 & $\mathrm{F} 2$ \\
\hline VA & 440 & 2144 & 584 & 1813 & 438 & 1512 \\
\hline VN & 363 & 2665 & 948 & 1623 & 382 & 952 \\
\hline
\end{tabular}

Tabela 1: Média da frequência dos formantes da vogal de apoio e da vogal núcleo em encontros consonantais tautossilábicos formados por consoante oclusiva $+[\mathrm{r}]$ em palavras isoladas.

Fonte: adaptado de Silveira e Seara (2008, p. 41)

Costa (2011), analisando o rotacismo, fenômeno de alternância entre a líquida e o rótico, em onsets complexos, observou a presença de duas variantes do rótico no onset de sílabas CCV: o tepe $(68,67 \%)$ e a aproximante $(27,22 \%)$, que foram as variantes mais frequentemente empregadas. Assim, dentre as produções esperadas de róticos em sílabas CCV, poderemos encontrar a produção de tepes, aproximantes e ainda de vibrantes ${ }^{4}$. Uma aproximante, diferentemente do tepe, não se caracteriza por um movimento de contato entre os articuladores, mas apenas de uma aproximação entre eles, podendo ocorrer ainda um contato de ponta de língua com superfície bastante reduzida. Acusticamente, essa consoante apresenta energia contínua. Observe, na Figura 2, um exemplo de produção de uma aproximante:

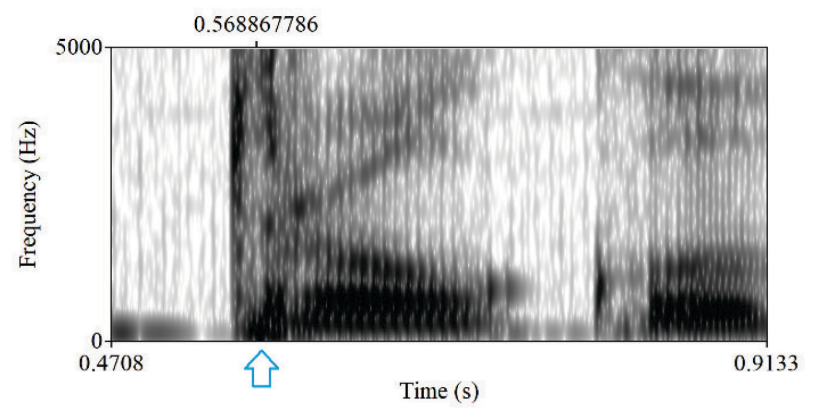

Figura 2: Espectrograma de um exemplo de produção de uma aproximante na palavra grato (fala infantil)

Fonte: elaboração dos autores

Na Figura 2, podemos verificar pelo espectrograma que há amplitude contínua entre a região do rótico (seta azul) e da vogal que o segue e não há nenhuma indicação de bloqueio oral.

\footnotetext{
${ }^{4}$ A observação da produção de vibrantes em onset complexo na fala adulta é bastante incomum, já que elas estariam apenas presentes em posição final de sílaba (coda silábica). No entanto, na inspeção dos dados das crianças aqui investigadas, foi observada a produção de vibrantes.
} 
Uma vibrante, assim como o tepe, possui, como características comuns, a presença de oclusão oral ou fechamento oral, descrito acusticamente pela baixa amplitude, e elementos vocálicos ou fechamentos orais, descritos como um contínuo em energia com estruturas formânticas. Observe, na Figura 3, um exemplo da produção de uma vibrante:

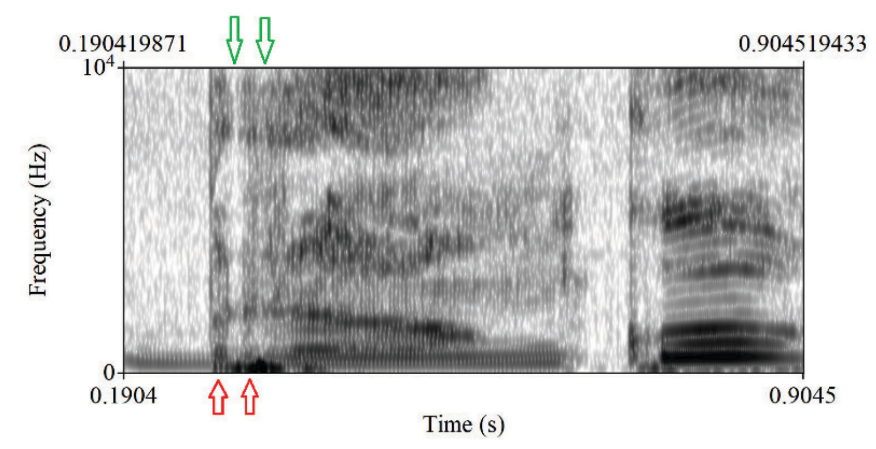

Figura 3: Espectrograma de um exemplo de produção de uma vibrante na palavra branco (fala infantil)

Fonte: elaboração dos autores

Na Figura 3, observamos as características acústicas de uma consoante vibrante, tais como regiões de baixa amplitude (setas verdes), que indicam o fechamento oral, e regiões de um contínuo com estruturas formânticas (setas vermelhas), indicando a abertura oral.

Outro elemento que compõe as sílabas em estudo, no caso de a primeira consoante ser uma oclusiva, é o Voice Onset Time (VOT) (KELLER, 1994; STEVENS, 1998; KLEIN, 1999; CRISTOFOLINI, 2013; dentre outros). As consoantes oclusivas não-vozeadas são produzidas com diferentes momentos: (a) uma obstrução total dos articuladores sem vibração das pregas vocais, (b) sua soltura da oclusão, gerando algumas vezes uma explosão (burst) e (c) uma fase de transição para o início da vogal. As consoantes oclusivas vozeadas são produzidas com os seguintes momentos: (a) uma obstrução total dos articuladores com a vibração simultânea das pregas vocais (vozeamento), (b) seguida pela soltura dessa oclusão, podendo também gerar uma explosão (burst). O VOT é uma medida de tempo que, para as oclusivas não-vozeadas, compreende os momentos (b) e (c). Para as oclusivas vozeadas, compreende os momentos (a) e (b).

As consoantes oclusivas do PB (bilabiais, dentais-alveolares e velares) são classificadas a partir de duas categorias de VOT: prévozeamento e retardo curto. O pré-vozeamento é assim denominado porque, como vimos anteriormente, as oclusivas vozeadas apresentam vozeamento antes da soltura da oclusão. Os valores de VOT de pré-vozeamento recebem um sinal negativo apenas para indicar que o vozeamento é anterior ao burst, pois, sendo o VOT uma medida de tempo, não poderia ser negativa. O retardo curto compreende um pequeno tempo entre a soltura e o início do vozeamento do segmento adjacente e ocorre em oclusivas nãovozeadas. Veja, na Figura 4(a), um exemplo de retardo curto e, na Figura 4(b), um exemplo de pré-vozeamento de oclusivas bilabiais não-vozeada e vozeada, respectivamente: 


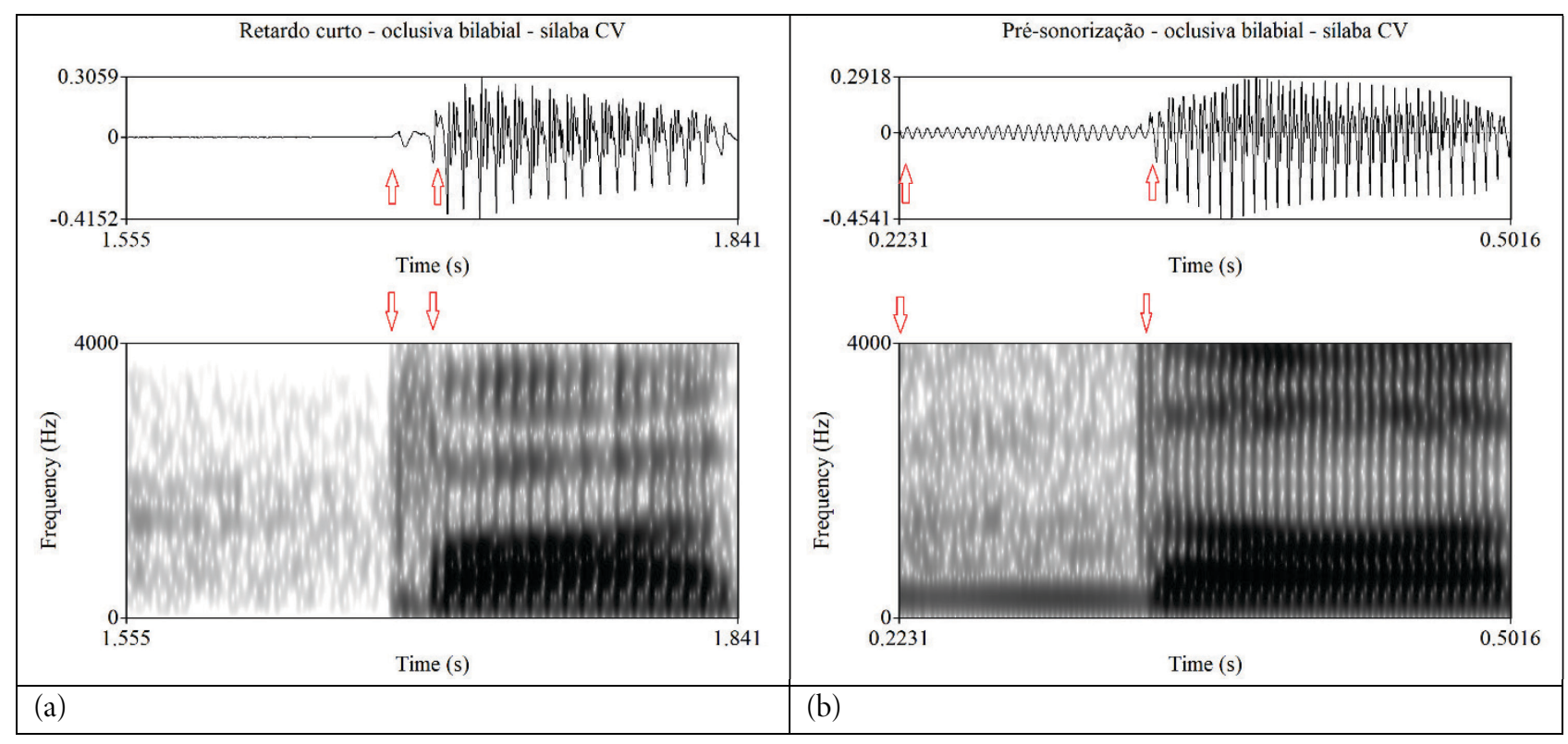

Figura 4: Forma-de-onda e espectrograma de oclusivas bilabiais (a) não-vozeada e (b) vozeada

Fonte: elaboração dos autores

Pela Figura 4, podemos observar as duas categorias de VOT do PB. O retardo curto, que neste caso corresponde a uma duração de $21 \mathrm{~ms}$, é exibido em (a) e compreende as regiões entre as duas setas vermelhas. O pré-vozeamento, que aqui corresponde a uma duração de (-)113ms, é exibido em (b) entre as duas setas vermelhas. Assim, a duração do VOT das consoantes oclusivas, produzidas pelos dois grupos de crianças, também será averiguada com a finalidade de observar se existem diferenças relevantes entre as produções das crianças em estudo.

Pesquisas sobre a produção de plosivas e fricativas na fala infantil típica também têm identificado produções que evidenciam que a fala infantil está em período de "refinamento articulatório" (CRISTOFOLINI, 2013; CEMIN, 2014; CEMIN; SEARA, 2017). Cristofolini (2013) realizou uma inspeção visual de segmentos plosivos e fricativos produzidos por grupos de crianças com fala típica com idades entre 6 e 12 anos, e fez um levantamento de características acústicas que diferiam do considerado habitual para os dados analisados. Seriam essas as características que perpassam o período de refinamento articulatório. A autora denominou essas características de especificidades acústicas ou características não habituais, e as definiu como: (a) segmentos plosivos não-vozeados com duplo burst; (b) plosivos não-vozeados com múltiplos bursts; (c) plosivos não-vozeados com vozeamento na porção do silêncio do segmento; (d) plosivos não-vozeados com burst vozeado; (e) plosivos não-vozeados totalmente vozeados; (f) plosivos vozeados com duplo burst; (g) plosivos vozeados com múltiplos bursts; (h) plosivos vozeados com interrupções no vozeamento na porção inicial do segmento; (i) plosivos vozeados com interrupção do vozeamento na porção medial do segmento; (j) plosivos vozeados com interrupções no vozeamento na porção final do segmento (CRISTOFOLINI, 2013).

Caracterizados os elementos a serem investigados no presente estudo, na seção a seguir, discorreremos sobre os procedimentos metodológicos.

\section{METODOLOGIA}

Os dados acústicos analisados neste estudo fazem parte do banco de dados coletado por Vassoler (2016). Na sequência, apresentamos o detalhamento da metodologia, considerando: participantes; corpus para gravação, procedimentos de coleta e etiquetagem dos dados; análise acústica e estatística dos dados. 


\subsection{PARTICIPANTES}

Seis crianças monolíngues e falantes do $\mathrm{PB}$, com idades entre 5 e 6 anos, constituem os sujeitos de pesquisa e foram avaliadas por um fonoaudiólogo da Clínica de Fonoaudiologia da UNESP (Marília, SP - Brasil), que auxiliou na constituição de dois grupos de crianças, caracterizados como de fala típica e de fala com desvio fonológico (fala atípica). Cada grupo foi composto por 3 crianças.

Os critérios de inclusão para selecionar as crianças com desvio fonológico foram: crianças com dificuldades de produção de encontro consonantal e ausência de comorbidades (tais como: presença de distúrbio de linguagem; de alterações anatômicas e morfológicas que prejudicam o processo de produção da fala - por exemplo, fissura labial e palatina). Os critérios de exclusão foram a presença de otologia e/ou alterações auditivas. E ainda, para ambos os grupos de crianças, os critérios de exclusão foram: presença de alterações intelectuais e neurológicas; presença de alterações anatomorfológicas que comprometam o processo de produção de fala (como, por exemplo, fissura lábio-palatina) e de alterações otológico/auditivas.

Tanto as crianças quanto seus responsáveis assentiram com o Termo de Consentimento Livre e Esclarecido (TCLE). Este estudo foi aprovado pela Comitê de Ética da Faculdade de Filosofia e Ciências - UNESP/Marília sob o nº 0974/2014 e foi pautado nas diretrizes e nas normas regulamentadoras de pesquisas, envolvendo seres humanos, determinadas pelo Conselho Nacional de Saúde nas resoluções 466/12 e 510/16, respectivamente.

\subsection{CORPUS E COLETA DE DADOS}

O corpus, contendo as sílabas-alvo CCV e CV, foi o mesmo utilizado por Miranda e Cristófaro-Silva (2011) $)^{5}$, que também pesquisavam a produção das sílabas CCV na fala infantil, cuja segunda consoante era uma líquida não-lateral. Veja, no Quadro 1, os pares de palavras gravados pelos dois grupos de crianças do presente estudo:

\begin{tabular}{c|c|c} 
Vogais-núcleo $^{6}$ & $\mathrm{CCV}$ & $\mathrm{CV}^{7}$ \\
\hline$[\mathrm{a}]$ & prato - grato & pato - gato \\
\hline$[\varepsilon]$ & prego - pressa & pego - peça \\
\hline$[\mathrm{i}]$ & frita & fita \\
\hline$[\mathrm{o}]$ & troca & toca \\
\hline$[\mathrm{o}]$ & broa - troco & boa - toco \\
\hline$[\mathrm{u}]$ & bruxa & bucha
\end{tabular}

Quadro 1: Palavras que formaram pares mínimos gravados pelos dois grupos de crianças (fala típica e com desvio fonológico)

Fonte: elaboração dos autores

A amostra de fala foi coletada com os seguintes equipamentos: ultrassom portátil, modelo DP 6600, contendo transdutor acoplado a um computador, microfone unidirecional e estabilizador de cabeça. Foram coletados 30 dados para cada participante, no entanto,

\footnotetext{
${ }^{5}$ As autoras tinham, como participantes, crianças entre 3:3 e 4:6 anos, portanto, mais jovens do que as que aqui pesquisamos.

${ }^{6}$ Remarcamos que, no corpus selecionado para o presente estudo, não havia par mínimo com a vogal [e].

${ }^{7}$ As palavras pego e toco foram solicitadas a serem produzidas como ['pego] e ['toku], respectivamente, uma vez que as palavras que completavam seus pares mínimos (prego e troco) foram produzidas como ['prego] e ['trokv], respectivamente.
} 
tivemos de descartar alguns desses dados em função de sua pouca qualidade, levando em conta as análises acústicas necessárias para o presente estudo. A Tabela 2 apresenta o número de dados de cada participante e de cada grupo:

\begin{tabular}{c|c|c|c|c|c|c|c|c}
\multirow{2}{*}{ Grupo } & \multicolumn{5}{|c|}{ Fala típica } & \multicolumn{4}{c}{ Fala atípica } \\
\hline Participante & T1 & T2 & T3 & Total & A1 & A2 & A3 & Total \\
\hline Número de dados & 29 & 29 & 26 & 84 & 29 & 30 & 30 & 89
\end{tabular}

Tabela 2: Número de dados coletados por participante e por grupo

Fonte: elaboração dos autores

Os dados foram capturados e analisados pelo Programa Articulate Assistant Advanced (ARTICULATE INSTRUMENTS, 2019). Os sinais acústicos e de imagem foram registrados simultaneamente com o uso do software AAA, acoplado a um sincronizador entre as imagens e os dados acústicos correspondentes. No presente estudo, trataremos apenas dos dados acústicos.

\subsection{ETIQUETAGEM DOS DADOS}

Os dados foram etiquetados em três camadas, considerando-se: na primeira camada, o tipo de rótico produzido, a vogal de apoio (VA) e a vogal-núcleo (VN) das sílabas CCV e CV, e o VOT. Na segunda camada, foram etiquetados os eventos acústicos que caracterizavam as produções de fala típica e atípica e, na terceira camada, a palavra produzida.

\subsection{ANÁLISE ACÚSTICA DOS DADOS}

Para a análise dos dados, utilizamos um script ${ }^{8}$ que coleta automaticamente os parâmetros aqui observados (duração e frequência). Por conta da brevidade de alguns dos segmentos aqui tratados, como, por exemplo, as vogais de apoio, este script coleta os dados em 5 pontos dentro de cada som analisado. Isso quer dizer que, dentro da região etiquetada como segmento em análise, foi usada a seguinte definição dos pontos de coleta dos formantes:

$$
\begin{aligned}
& \text { \#inicio do segmento (tp1) } \\
& \text { tp1 = tp_ini } \\
& \text { \#fim do segmento (tp5) } \\
& \text { tp5 = tp_fim } \\
& \text { \#meio do segmento }(\mathrm{tp} 2, \mathrm{tp} 3, \mathrm{tp} 4) \\
& \text { tp3 }=(\text { tp_ini+tp_fim }) / 2 \\
& \text { tp2 }=(\text { tp_ini+tp3) } / 2 \\
& \text { tp4 }=(\text { tp3+tp_fim }) / 2
\end{aligned}
$$

Essa quantidade de pontos coletados nos permitiu a verificação da consistência de cada um deles e o descarte daqueles que tenham sido coletados inadequadamente pela má resolução do algoritmo de análise das frequências, em função da brevidade desses sons. Na maior parte dos casos, foram coletados os formantes referentes ao ponto medial do segmento (tp3). Tanto as etiquetagens quanto as análises dos dados foram feitas a partir do software de análise de fala PRAAT (BOERSMA; WENINK, 2016).

\footnotetext{
${ }^{8}$ Script desenvolvido por Fernando Santana Pacheco (2008).
} 


\subsection{ANÁLISE ESTATÍSTICA}

Com o auxílio do software R (R CORE TEAM, 2020), foi verificado o grau de correlação entre as durações da vogal de apoio e da vogal núcleo com o Coeficiente de Correlação de Pearson. A classificação do grau de correlação (r), ou seja, da força entre as variáveis foi analisada a partir dos seguintes parâmetros: fraco, quando $0<\mathrm{r} \leq 0,4$; moderado, quando $0,4<\mathrm{r} \leq 0,7$; e forte, quando $0,7<\mathrm{r} \leq$ 1,0. A comparação entre as durações relativas das vogais de apoio e núcleo foi feita pela Análise Anova Multivariada e pelo teste post hoc scheffe. Foram consideradas correlações com significância estatística as que apresentaram $p \leq 0,05$.

Com as medidas de VOT, foram utilizados testes-t de uma amostra e de duas amostras não-pareadas, rodados no $\mathrm{R}$ (R CORE TEAM, 2020). Por fim, com os dados de ocorrência dos eventos acústicos, um teste de qui-quadrado foi também conduzido no $\mathrm{R}$ (R CORE TEAM, 2020).

\section{RESULTADOS E DISCUSSÃO}

Nesta seção, apresentaremos os resultados das análises dos róticos, da vogal de apoio, do VOT, das vogais núcleo em sílabas CCV e $\mathrm{CV}$ e, finalmente, dos eventos acústicos observados na fala típica e atípica

\subsection{RÓTICOS}

Dentre as produções de róticos apresentadas pelo grupo de crianças típicas, verificou-se a presença de vibrantes como segunda consoante de sílabas $\mathrm{C}_{1} \mathrm{C}_{2} \mathrm{~V}$. Esse tipo de rótico em sílabas CCV não é habitual na fala adulta, sendo, nesse caso, geralmente encontrado apenas em onset simples e em coda silábica. No entanto, as vibrantes produzidas pelas crianças corresponderam a $21 \%$ dos dados.

Além das vibrantes, foi observada também uma única produção de um tepe espirantizado na palavra bruxa. Espirantização envolve sobreposição de ruído fricativo (SILVA, 2002) em diferentes graus. Observe a Figura 5:

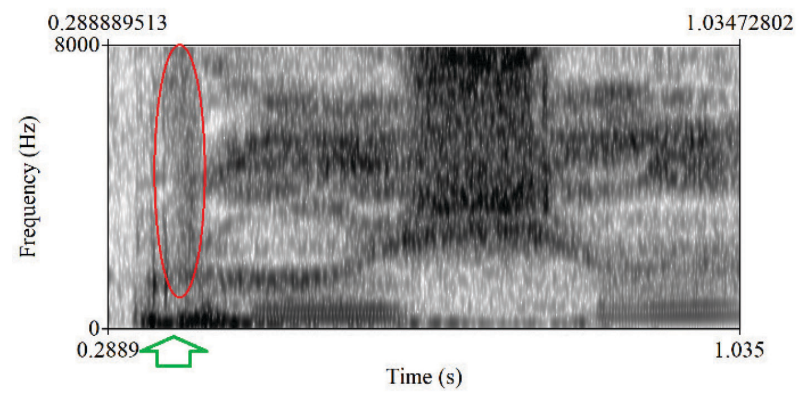

Figura 5: Espectrograma do tepe espirantizado, produzido por uma das crianças de fala típica na palavra bruxa.

Fonte: elaboração das autoras

$\mathrm{Na}$ Figura 5, é possível visualizar um ruído fricativo na região circulada em vermelho. Essa sobreposição de ruído sobre o rótico produzido (na seta verde) caracteriza-o como espirantizado. Esse tipo de produção também ocorre em dados de fala adulta.

Apresentamos, na Tabela 3, os resultados referentes a todos os róticos produzidos por cada uma das seis crianças em sílabas CCV, foco de nossa investigação: 


\begin{tabular}{|c|c|c|c|c|c|c|c|c|}
\hline \multirow{2}{*}{ Rótico } & \multicolumn{4}{|c|}{ Fala típica } & \multicolumn{4}{|c|}{ Fala atípica } \\
\hline & $\mathrm{T} 1$ & $\mathrm{~T} 2$ & $\mathrm{~T} 3$ & Total & Al & A2 & A3 & Total \\
\hline tepe & 08 & 10 & 14 & $38 \%$ & 0 & 0 & 0 & $0 \%$ \\
\hline tepe espirantizado & 01 & 0 & 0 & $2 \%$ & 0 & 0 & 0 & $0 \%$ \\
\hline vibrante & 12 & 06 & 0 & $21 \%$ & 0 & 0 & 0 & $0 \%$ \\
\hline aproximante & 05 & 12 & 09 & $31 \%$ & 0 & 0 & 0 & $0 \%$ \\
\hline produções sem r & 03 & 01 & 03 & $8 \%$ & 29 & 30 & 30 & $100 \%$ \\
\hline Total & 29 & 29 & 26 & $100 \%$ & 29 & 30 & 30 & $100 \%$ \\
\hline
\end{tabular}

Tabela 3: Produções de róticos apresentadas pelos dois grupos de crianças em sílabas CCV.

Fonte: elaboração dos autores

$\mathrm{Na}$ Tabela 3, são exibidas as frequências de ocorrência dos tipos de róticos produzidos por cada grupo de crianças (fala típica e atípica). Nessa tabela, é possível verificar que crianças com desvio fonológico (fala atípica) não apresentaram o rótico em nenhuma de suas produções de sílabas CCV. No entanto, nas produções de crianças de fala típica, a ausência do rótico foi observada em apenas $8 \%$ dos dados.

Ainda, pela Tabela 3, podemos observar que os róticos mais frequentes produzidos pelas crianças de fala típica foram: o tepe (38\%), conforme Figura 1, a aproximante (31\%), conforme Figura 2, e a vibrante (21\%), conforme Figura 3.

\subsection{VOGAL DE APOIO E VOGAL NÚCLEO EM SÍLABAS C+[r]+V}

Considerando agora apenas as produções de tepes, analisaremos as frequências de ressonância (formantes) - F1 e F2 - das vogais de apoio e das vogais núcleo, apresentadas nas produções das crianças de fala típica. Observe a Figura 6: 


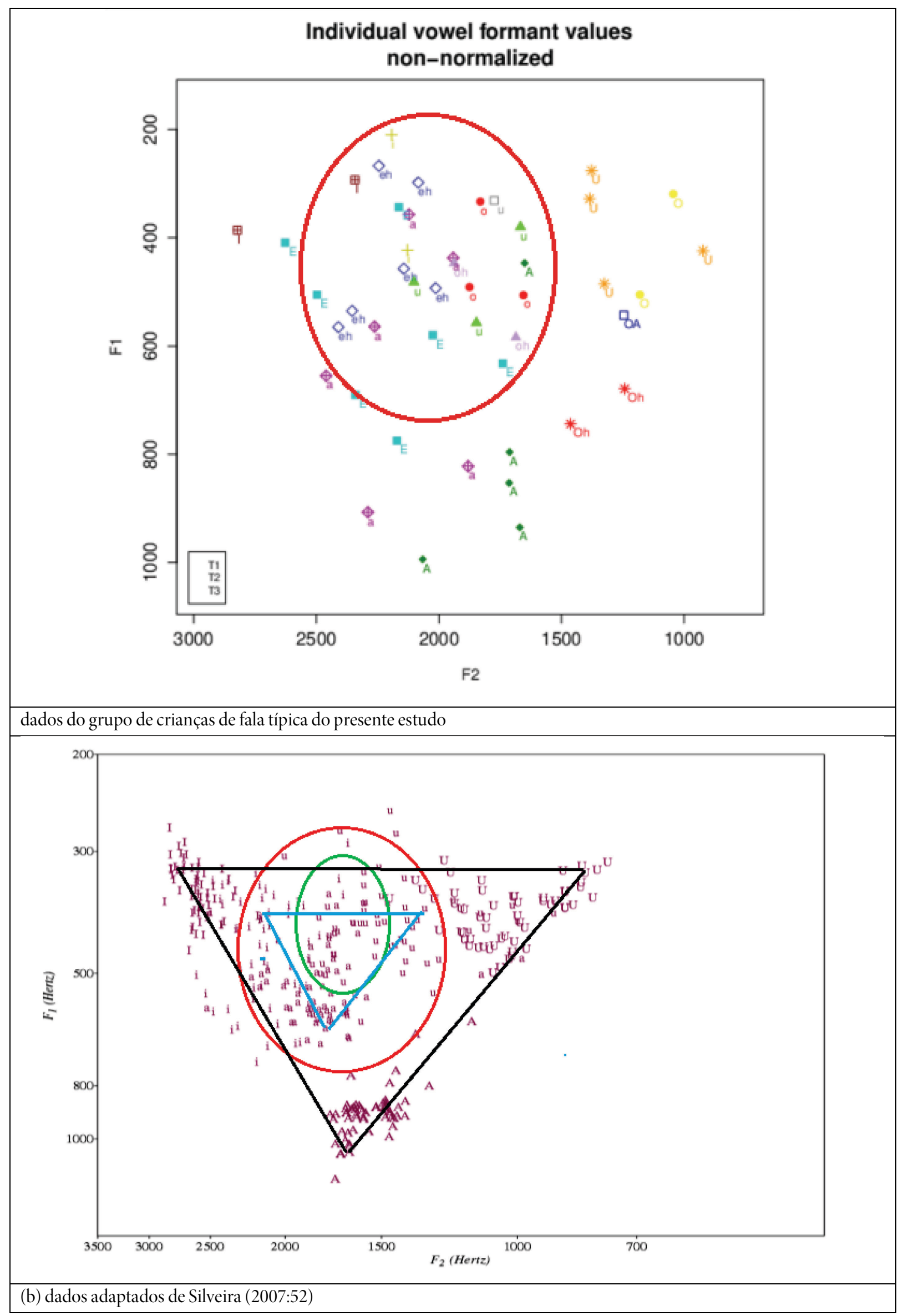


Figura 6: Espaço acústico vocálico (F1 x F2) das vogais de apoio (em minúsculas) e das vogais núcleo (em maiúsculas): (a) dados das crianças com fala típica investigadas ; (b) dados analisados em Silveira (2007), adaptados, a partir da produção de adultos femininos

Fonte: em (a) elaboração das autoras; em (b) adaptado de Silveira (2007, p. 52)

Na Figura 6, foi feita a plotagem de dados referente aos dois primeiros formantes vocálicos das vogais de apoio e das vogais núcleo das sílabas CCV: em (a), produzidas pelas crianças do grupo de fala típica e, em (b), por mulheres adultas, analisadas em Silveira (2007:52). Pelos gráficos, podemos observar que, assim como colocado por Silveira (2007), os dados das crianças (círculo vermelho em 6(a)) e das mulheres (círculo verde em 6(b)), referentes às vogais de apoio, se mostram centralizados. Nos dados apresentados por Silveira (2007) (Figura 6(b)), verificamos que a maior parte das vogais de apoio parece indicar uma redução do espaço vocálico (triângulo em azul na Figura 6(b)), quando comparado ao espaço vocálico das vogais núcleo (triângulo em preto na Figura 6(b)). Silveira e Seara (2008) ratificam essa colocação quando dizem que os formantes vocálicos (F1 e F2) das vogais de apoio são diferentes dos formantes apresentados pelas vogais núcleo correspondentes, apesar de evidenciarem qualidade vocálica da vogal do núcleo. As autoras encontraram diferenças para a vogal alta anterior e a baixa (teste $t \operatorname{com} p<0,001$ ). Nesses casos, verificaram que a vogal de apoio que antecede uma vogal núcleo alta anterior é também vogal alta anterior, porém menos alta e menos anterior do que a vogal núcleo correspondente; e a vogal de apoio que antecede a vogal núcleo baixa é uma vogal de apoio menos baixa. Todavia, nos dados da fala adulta, um certo número de vogais de apoio exibe uma sobreposição no espaço acústico vocálico (círculo em verde na Figura 6(b)), situando-se em uma região bastante centralizada.

Ao observarmos os dados das crianças com fala típica, veremos que não podemos ratificar a redução do espaço acústico vocálico, encontrada nos dados de Silveira (2007), haja vista a centralização bastante evidente das vogais de apoio em relação às vogais núcleo das sílabas CCV, evidenciando uma grande sobreposição das vogais de apoio (círculo em vermelho na Figura 6(a)), produzidas pelas crianças de fala típica. Nos casos em que há sobreposição, parece ficar evidente a produção de vogais centralizadas. Nesse ponto, a produção das crianças de fala típica apresenta semelhanças com a produção adulta; no entanto, também se diferencia por não apresentar redução no espaço acústico das vogais de apoio, conforme indicado em dados de fala adulta.

Passemos agora à análise temporal, investigando se as durações absoluta e relativa das vogais em estudo estão correlacionadas, conforme apontado por Silveira (2007) para os dados de adultos. Segundo a autora, quanto maior a vogal núcleo, maior a vogal de apoio.

Na Tabela 4, apresentamos os resultados das análises da duração das vogais de apoio e suas correspondentes vogais núcleo. Outros estudos (SILVEIRA e SEARA, 2008; NISHIDA, 2009; RAMÍREZ, 2006) observaram que a duração das vogais de apoio apresentou diferenças estatisticamente significativas em relação à duração da vogal núcleo e que a duração das vogais de apoio tem, em média, um terço da duração das vogais núcleo, ou seja, em torno de 30\%. Calculamos também, para os nossos dados, a duração relativa da vogal de apoio com respeito à vogal núcleo $(\mathrm{VA} / \mathrm{VNx} 100)$ e os resultados mostraram que as vogais de apoio produzidas pelas crianças de fala típica são bem menores do que as produzidas pelos adultos, uma vez que correspondem, em média, a $12 \%$ da duração das vogais núcleo, tanto considerando a duração absoluta dessas vogais, quanto a duração relativa ${ }^{10}$.

\footnotetext{
${ }^{9}$ A plotagem desses dados (em Hertz) foram obtidas a partir do site de normalização, disponível em: http:/lingtools.uoregon.edu/norm/norm1.php. Nessa plotagem, não foi feita a normalização para que se pudesse compará-la aos dados apresentados em Silveira (2007, p. 52).

${ }^{10}$ Lembramos que a duração relativa das vogais de apoio e núcleo foram calculadas, para normalização, em relação à duração das palavras, já que todas as palavras são dissilábicas.
} 


\begin{tabular}{c|c|c|c|c|c|c}
\multirow{2}{*}{ Vogais } & \multicolumn{3}{|c|}{ Duração absoluta (em ms) } & \multicolumn{3}{c}{ Duraça relativa (\%) } \\
\cline { 2 - 7 } & VN & VA & $($ VA/VNx100) & VN & VA & $($ VA/VNx100) \\
\hline$[\mathrm{a}]$ & 187 & 17 & $9 \%$ & 36,00 & 3,58 & $10 \%$ \\
\hline$[\varepsilon]$ & 214 & 27 & $13 \%$ & 34,01 & 4,18 & $12 \%$ \\
\hline$[\mathrm{i}]$ & 160 & 22 & $14 \%$ & 22,59 & 3,88 & $18 \%$ \\
\hline$[0]$ & 118 & 14 & $12 \%$ & 27,04 & 3,20 & $12 \%$ \\
\hline$[\mathrm{o}]$ & 286 & 37 & $13 \%$ & 49,03 & 6,17 & $13 \%$ \\
\hline$[\mathrm{u}]$ & 243 & 23 & $10 \%$ & 30,43 & 2,70 & $9 \%$
\end{tabular}

Tabela 4: Duração absoluta (ms) e relativa (\%) das vogais de apoio e núcleo emitidas pelas crianças de fala típica que produziram o tepe como segunda consoante de sílabas CCV

Fonte: elaboração dos autores

$\mathrm{Na}$ análise do parâmetro duracional, foi verificado que, diferentemente do encontrado na fala adulta em que há correlação positiva entre a duração desses dois elementos vocálicos, ou seja, quanto maior a vogal núcleo, maior a vogal de apoio (SILVEIRA, 2007), nossos resultados apontaram não haver correlação entre essas vogais $(-0,09)$. Esses dados mostram novamente diferenças em relação à fala adulta.

Apresentados os resultados concernentes às sílabas CCV que foram produzidas com o tepe que corresponderam apenas a dados de crianças do grupo de fala típica, já que as de fala atípica não produziram o rótico, passemos às análises temporais que envolvem o VOT das oclusivas e as vogais núcleo das sílabas CCV e CV, produzidas na fala dos dois grupos de crianças (típico e atípico).

\subsection{VOICE ONSET TIME}

Levando em conta que, no estudo de Vassoler (2016) com os mesmos informantes, não foram observadas diferenças estatísticas nas durações de sílabas CCV entre crianças dos grupos de fala típica e atípica, vamos averiguar os elementos internos às sílabas, ou seja, a duração do VOT e das vogais do núcleo das sílabas CCV. Nesse caso, nosso objetivo é verificar se existem diferenças entre os dados dos dois grupos que possam indicar que as crianças com a fala atípica apresentam características em suas produções que parecem sugerir o seu conhecimento fonológico quanto à presença de um segmento que ainda não é produzido por elas. Vamos então seguir na busca por mais indícios dessa questão, averiguando primeiramente os valores de VOT (Voice Onset Time) das consoantes oclusivas, que eram maioria ${ }^{12}$ nos pares de palavras produzidos.

\footnotetext{
${ }^{11}$ Salientamos que alguns resultados de duração não espelham o que ocorre na fala adulta e acreditamos que isso tenha ocorrido por conta do refinamento motor ainda necessário para a produção dos sons em análise. Isso parece ter trazido também alterações nas produções das vogais, por exemplo, a vogal aberta [0], que apresenta duração intrínseca menor do que as fechadas. Essas alterações parecem ter sido a razão da falta de correlação entre os resultados da vogal de apoio e da vogal do núcleo.

${ }^{12}$ Das 20 palavras do corpus, apenas duas apresentam como primeira consoante uma fricativa (frita-fita). As demais eram constituídas por oclusivas, conforme vimos no Quadro 1 na seção de Metodologia.
} 
Com base nas duas categorias de VOT (retardo curto e pré-vozeamento ${ }^{13}$ ), vistas na Seção 2, coletamos as durações das regiões de VOT das produções dos dois grupos de crianças. Iniciamos esta discussão com a Tabela 5, que apresenta os valores médios de duração relativa ${ }^{14}$ do VOT, obtidos em nossos dados em sílabas CCV e CV, e daqueles obtidos por Cristofolini (2013) para adultos e crianças com fala típica com 6 anos de idade, em sílabas CV. Esses últimos dados nortearão as observações de nossos resultados.

\begin{tabular}{|c|c|c|c|c|c|c|}
\hline \multirow{4}{*}{$\begin{array}{c}\text { Consoantes } \\
{[p]}\end{array}$} & \multicolumn{6}{|c|}{ Duração relativa (\%) do VOT } \\
\hline & Adultos & Crianças de 6 anos & \multicolumn{2}{|c|}{ Fala típica } & \multicolumn{2}{|c|}{ Fala atípica } \\
\hline & \multicolumn{2}{|c|}{ Cristofolini (2013, p. 138-154) } & $\mathrm{CCV}$ & $\mathrm{CV}$ & $\mathrm{CCV}$ & $\mathrm{CV}$ \\
\hline & 5,80 & 4,90 & 2,96 & 4,34 & 4,70 & 5,45 \\
\hline$/ b / \rightarrow[p]$ & - & - & 2,05 & 5,24 & 6,52 & 5,42 \\
\hline$[\mathbf{t}]$ & 4,50 & 4,10 & 4,49 & 4,48 & 5,29 & 5,18 \\
\hline$[\mathrm{k}]$ & 10,10 & 9,5 & - & - & - & - \\
\hline$/ g / \rightarrow[\mathrm{k}]$ & - & - & 3,56 & 2,50 & 9,26 & 8,48 \\
\hline$[b]$ & 24,20 & 24,50 & 13,90 & 17,58 & 20,75 & 22,51 \\
\hline [d] & 22,80 & 21,00 & - & - & - & - \\
\hline$/ g / \rightarrow[d]$ & - & - & 6,83 & 2,75 & - & - \\
\hline$[g]$ & 21,30 & 20,70 & 17,84 & 16,41 & 24,27 & 19,27 \\
\hline
\end{tabular}

Tabela 5: Valores médios de duração relativa do VOT das oclusivas não-vozeadas e vozeadas de sílabas CCV e CV nas produções de crianças de fala típica e atípica e em Cristofolini (2013, p. 138-154) nas produções de adultos e crianças de 6 anos, em sílabas CV

Fonte: elaboração dos autores e adaptado de Cristofolini (2013, p. 138-154)

Os dados de Cristofolini (2013) de pré-vozeamento mostram que os valores de VOT das oclusivas vozeadas parecem indicar que as velares apresentam valores mais baixos quando comparadas às bilabiais e alveolares (comportamento semelhante ao de outros estudos como KLEIN, 1999; PRESTES, 2013; CEMIN, 2014, dentre outros), havendo, no entanto, diferenças significativas entre as oclusivas vozeadas produzidas pelas crianças e pelos adultos ${ }^{15}$. Os dados da autora mostram ainda que, para o retardo curto, os valores de VOT das velares apresentam-se agora mais altos do que os das bilabiais e alveolares (conforme também apontam estudos como os de KLEIN, 1999; PRESTES, 2013; CEMIN, 2014; dentre outros) e que, entre as oclusivas não-vozeadas [p] e [k], também foram registradas diferenças estatisticamente significativas ${ }^{16}$ entre as produções de adultos e crianças. Com esses apontamentos, passemos aos resultados obtidos em nosso estudo. A Figura 7 apresenta a plotagem de VOT das sílabas CCV e CV pelas crianças típicas e com desvio fonológico. As linhas pontilhadas em vermelho são os valores das crianças de Cristofolini (2013) e as linhas pontilhadas em azul são os dos adultos, para servirem de referência.

\footnotetext{
${ }^{13}$ Salientamos novamente que, apesar de o pré-vozeamento ser anotado pelo sinal negativo para indicar que o vozeamento iniciou antes do burst, consideraremos apenas valores positivos, uma vez que representam medidas de tempo que são sempre positivas. Sendo assim, os valores apresentados representam o tempo de prévozeamento.

${ }^{14}$ Lembramos que, no presente estudo e nos dados de Cristofolini (2013), os valores de duração relativa do VOT foram calculados com referência à palavra.

${ }^{15} p=0,0013$ para [b]; $p=0,0019$ para [d] e $p=0,0175$ para [g] (CRISTOFOLINI, 2013, p.100).

${ }^{16} p=0,0209$ para $[\mathrm{p}]$ e $p=0,0129$ para $[\mathrm{k}]$ (CRISTOFOLINI, 2013, p.100).
} 


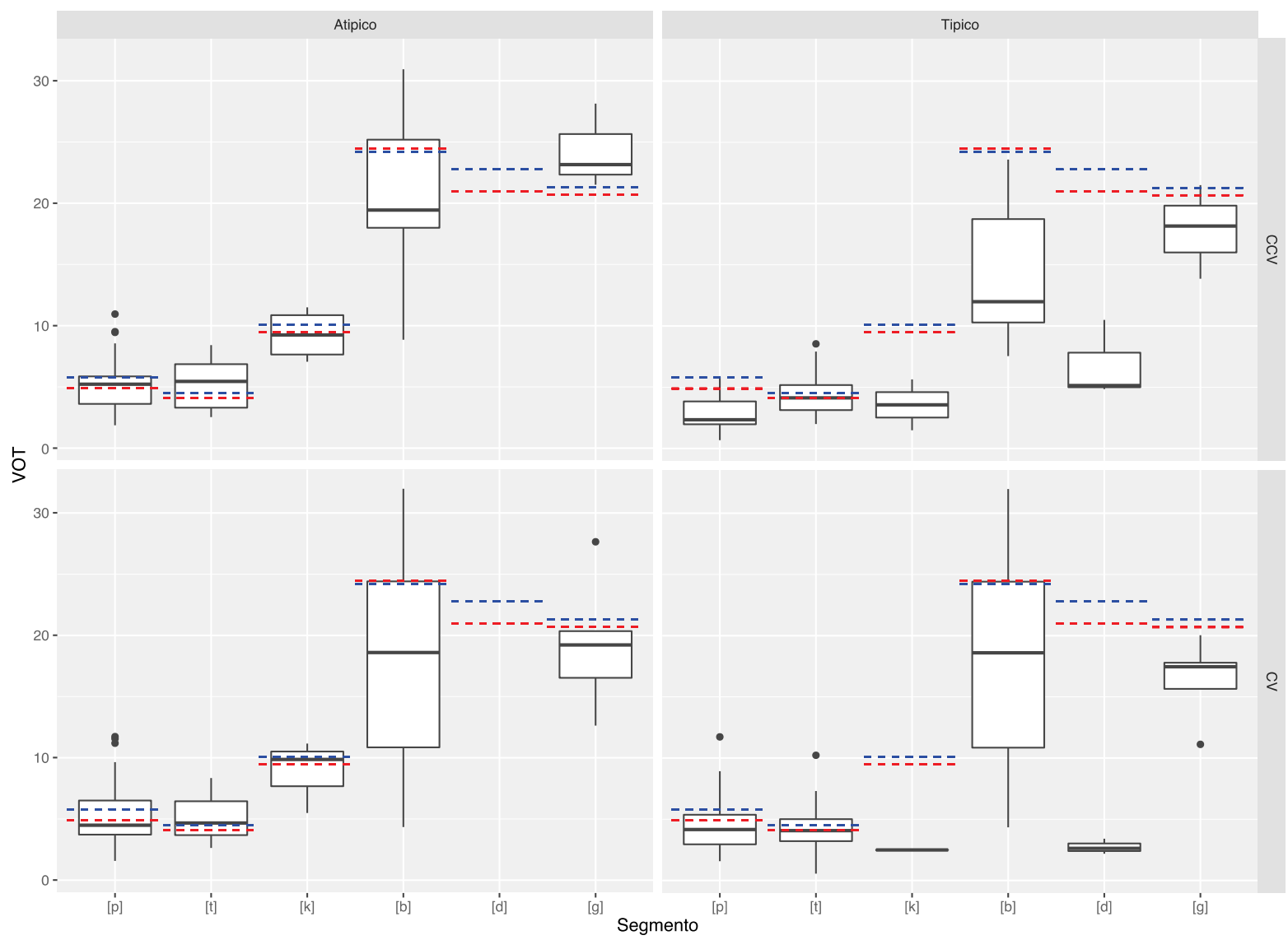

Figura 7: Gráfico de caixas do VOT dos padrões silábicos (CV e CCV) produzidos pelas crianças típicas e com desvio fonológico para cada segmento em comparação aos dados de Cristofolini (2013) nas linhas pontilhadas

Fonte: elaboração dos autores

Os dados dos dois grupos de crianças (típicas e com desvio fonológico), apresentados na Tabela 5, mostram alguma inconsistência com dados apresentados em Cristofolini (2013) para as crianças de 6 anos, uma vez que apresentaram comportamento variado. Para as crianças de fala atípica, como não foram produzidas sílabas $\mathrm{CCV}$, apenas $\mathrm{CV}$, o comportamento dos dados assemelha-se aos dados das crianças pesquisadas em Cristofolini (2013) - linhas pontilhadas vermelhas na Figura7, em especial para as não-vozeadas. Ainda se comparamos apenas os dados das sílabas CCV, observamos que o VOT produzido pelas crianças com desvio fonológico, ou seja, cujas sílabas CCV não apresentaram o rótico em nenhuma de suas produções, mostra-se mais alto do que o VOT do grupo de crianças de fala típica, com diferença estatisticamente significativa para as bilabiais em testes-t de duas amostras não-pareados ${ }^{17}$.

Desse fato, surge a seguinte pergunta: estaria essa diferença relacionada à consciência fonológica de um elemento que deveria estar presente na sílaba CCV, mas que não foi produzido e daí um VOT mais longo? Para buscar uma resposta, comparamos também o VOT de sílabas CCV produzido pelo grupo de fala típica com o grupo de crianças pesquisado por Cristofolini (2013) para sílabas CV e averiguamos que o VOT de sílabas CCV do grupo de fala típica tendeu a ser mais curto, com exceção de [t], que não foi significativo. No teste-t de uma amostra, comparando os valores dos participantes do presente estudo aos de Cristofolini (2013), os valores de VOT de $\left[\mathrm{pb} d\right.$ dos participantes da presente pesquisa foram estatisticamente mais curtos ${ }^{18}$. Talvez se possa inferir desses resultados que, em sílabas CCV, haja a necessidade de redução do VOT para a produção da segunda consoante da sílaba. Como não encontramos, na literatura, dados de VOT coletados em sílabas CCV, apenas apontamos para essa possibilidade. Por outro lado, os

\footnotetext{
${ }^{17}[\mathrm{p}] \mathrm{t}=-4,3 ; p<0,001 ;[\mathrm{b}] \mathrm{t}=-3,2 ; p=0,004$. Para os demais segmentos, a diferença não foi significativa.

${ }^{18}[\mathrm{p}] \mathrm{t}=-5,1 ; p<0,001 ;[\mathrm{b}] \mathrm{t}=-8,1 ; p<0,001 ;[\mathrm{d}] \mathrm{t}=-7,7 ; p<0,001$. Para os demais segmentos, a diferença não foi significativa.
} 
dados de VOT das sílabas CCV das crianças de fala atípica talvez possam indicar o alongamento compensatório, frequentemente utilizado como uma estratégia de reparo pelas crianças com desvio fonológico (DIAS, 2009; BRASIL, 2010; BELANDO et al., 2018).

Observamos ainda que houve trocas de oclusivas, com /g/produzido como [k], /b/ produzido como [p] e /g/ produzido como [d]. Nesses casos, os dados referentes às produções de vozeadas como não-vozeadas $(/ \mathrm{g} / \rightarrow[\mathrm{k}], / \mathrm{b} / \rightarrow[\mathrm{p}])$ apresentam inconsistência com o esperado apenas para as crianças com fala típica, uma vez que, para o retardo curto, exibiram valores bem mais baixos do que os esperados para as velares se comparadas às bilabiais e alveolares. Já para o pré-vozeamento, os valores das alveolares são mais baixos do que os das bilabiais e velares.

Outro aspecto que ainda deve ser destacado é referente às produções das crianças com fala típica que, quanto ao VOT, mostraram menos consistência nos resultados do que as crianças com desvio fonológico. Esse fato talvez possa ser justificado pelas suas produções de sílabas CCV, mesmo que ainda necessitem de um refinamento articulatório, ou seja, a produção da segunda consoante do onset silábico trouxe maior instabilidade para as configurações acústicas das primeiras consoantes desse onset. Os dados ultrassonográficos coletados juntamente com os dados acústicos aqui apresentados podem, em trabalhos futuros, dar mais indícios do que pode ter levado a tais inconsistências.

\subsection{VOGAIS NÚCLEO EM SÍLABAS CCV E CV}

Nossos resultados com respeito à duração relativa das vogais núcleo de sílabas CCV e CV são apresentados na Tabela 6:

\begin{tabular}{c|c|c|c|c}
\multirow{2}{*}{ Vogais } & \multicolumn{2}{|c|}{ Típica } & \multicolumn{2}{c}{ Atípica } \\
\cline { 2 - 5 } & CCV & CV & CCV & CV \\
\hline$[\mathrm{a}]$ & 35,53 & 37,11 & 42,34 & 39,19 \\
\hline$[\varepsilon]$ & 34,91 & 35,73 & 37,04 & 39,15 \\
\hline$[\mathrm{i}]$ & 21,44 & 21,45 & 25,60 & 27,63 \\
\hline$[0]$ & 29,64 & 29,60 & 35,11 & 35,82 \\
\hline$[\mathrm{o}]$ & 29,39 & 31,36 & 33,29 & 33,65 \\
\hline$[\mathrm{u}]$ & 32,81 & 31,58 & 31,10 & 24,82 \\
\hline
\end{tabular}

Tabela 6: Valores médios de duração relativa de vogais núcleo de sílabas CCV e CV produzidas pelos grupos de fala típica e atípica

Fonte: elaboração dos autores

Com os dados de duração relativa das vogais do núcleo das sílabas CCV em conjunto, comparamos as vogais produzidas pelas crianças dos dois grupos em estudo. Atestamos então que a duração relativa das vogais elocucionadas pelas crianças do grupo de fala atípica foi mais longa do que aquelas produzidas pelo grupo de crianças de fala típica $(\mathrm{F}(2,0)=22,50, p=0,065)$. Esse valor de $p$ caracteriza uma evidência sugestiva de diferença (ARSHAM, 1988) ${ }^{19}$ entre os valores de duração relativa da vogal que nos permite considerar que as crianças de fala atípica produzem vogais mais longas na tentativa de compensar a falta do rótico como segunda consoante da sílaba CCV, conforme também já observado para a fala infantil em Miranda e Cristófaro-Silva (2011). Agrega-se a essa observação a duração relativa dos VOTs das oclusivas que também se apresentaram mais longos em sílabas CCV para o grupo de

\footnotetext{
${ }^{19}$ Para esse autor, valores de $p$ entre 0,05 e 0,10 é interpretado como evidência sugestiva contra a hipótese nula $\left(\mathrm{H}_{0}\right)$.
} 
fala atípica. Aparentemente, as produções do grupo de fala típica, por apresentarem o rótico, reduzem a duração do VOT e da vogal núcleo, para que a duração da sílaba se mantenha adequada ${ }^{20}$.

Feitas as investigações concernentes aos padrões temporais, vamos agora observar os eventos acústicos presentes na fala dos dois grupos de crianças.

\subsection{EVENTOS ACÚSTICOS OBSERVADOS NA FALA TÍPICA E ATÍPICA}

Nossa primeira observação diz respeito ao desvozeamento de consoantes vozeadas. Produções de oclusivas desvozeadas são bastante frequentes na fala infantil (CRISTOFOLINI, 2013; CEMIN, 2014). Isso acontece porque consoantes vozeadas requerem um maior refinamento articulatório para que haja vibração das pregas vocais. Quando há vozeamento, é preciso que as pregas vocais tenham um grau adequado de tensão e de adução, e o fluxo de ar deve passar pelas pregas vocais. O vozeamento pode ser mantido durante a produção de consoantes oclusivas vozeadas por um certo tempo, porém, para isso, deve haver vários outros movimentos que possibilitem a vibração das pregas vocais, como a expansão do trato vocal, proporcionando mais espaço ao ar acumulado, evitando que a pressão subglotal fique abaixo do nível necessário para a vibração das pregas.

Essa expansão pode ser passiva, pois as superfícies do trato vocal têm elasticidade, mas também pode ser ativa, através do abaixamento da laringe ou da expansão das paredes da faringe, outros movimentos necessários à vibração das pregas vocais. Há línguas, inclusive, que tornam as oclusivas vozeadas pré-nasalizadas como recurso de apoio (venting) à vibração das pregas vocais (e, por conseguinte, do vozeamento) (KHARLAMOV, 2018; KONG et al., 2012). Essa outra forma de expansão é chamada de restrição de vozeamento aerodinâmico (AVC). Nesse caso, a ventilação da pressão oral é realizada a partir da abertura da cavidade nasal, com o abaixamento do véu do palato. Essa abertura nasal ainda seria compatível com a produção de consoantes oclusivas vozeadas, desde que o fechamento velofaríngeo ocorresse cerca de $20 \mathrm{~ms}$ antes da abertura da oclusão oral dessas consoantes (OHALA, 1997).

Assim, considerando os gestos necessários à vibração das pregas vocais, é possível entender o porquê de as crianças terem maiores dificuldades de produção de consoantes vozeadas. Observando os resultados obtidos, vemos que a maior parte das produções dos dois grupos foram de consoantes não-vozeadas, muitas delas em função do desvozeamento. Nossos dados eram compostos por $60 \%$ de consoantes iniciais de sílabas não-vozeadas e 40\% de vozeadas. No entanto, o percentual de consoantes vozeadas produzido foi de $32 \%$ para o grupo de fala típica e de $29 \%$ para o grupo de fala atípica. Esses resultados evidenciam a complexidade de movimentos articulatórios envolvidos na produção de consoantes vozeadas em função das necessidades aerodinâmicas que possibilitam a vibração das pregas vocais.

Passemos então à verificação de outros eventos acústicos presentes nas produções dos sujeitos desta pesquisa. Nosso objetivo é observar se, na produção dos dois grupos de crianças, determinados eventos acústicos que não são previstos na produção típica adulta seriam mais frequentes em sílabas CCV ou CV. Investigamos ainda se tais eventos seriam mais presentes em produções de crianças com desvio fonológico, uma vez que seria esperado que essas crianças evidenciassem gestos menos refinados indicados por um maior número de eventos acústicos não habituais em comparação às produções de crianças com fala típica.

Já havíamos visto que Cristofolini (2013), pesquisando as características de oclusivas e fricativas, vozeadas e não-vozeadas, na fala de crianças de 6 a 12 anos, detalhou acusticamente essas consoantes e verificou que, após o período de aquisição fonológica, as crianças ainda apresentavam um período, chamado pela autora, de refinamento articulatório. Essa constatação baseou-se em especificidades acústicas, ou seja, características diferentes do considerado habitual na produção desses segmentos. Dentre essas

\footnotetext{
${ }^{20}$ Sobre a questão de alongamento ou encurtamento de segmentos sonoros em uma sílaba, existem muitos condicionamentos a se levar em conta, como, por exemplo, a qualidade da vogal e o modo de articulação das consoantes presentes na sílaba. No entanto, encontramos um estudo com foco em modelos de duração para a síntese de fala (O'SHAUGHNESSY,1981) que observou, em clusters consonantais, uma mudança na duração das consoantes do cluster, podendo haver diminuição de suas durações.
} 
especificidades acústicas ${ }^{21}$, encontramos em nossos dados: oclusivas vozeadas com interrupção de vozeamento na porção final do segmento e fricativas não-vozeadas com irregularidades no vozeamento (eventos renomeados no presente estudo como bloqueios orais ${ }^{22}$ ) e oclusivas vozeadas e não-vozeadas com duplos ou múltiplos bursts (os eventos duplos ou múltiplos bursts foram renomeados no presente estudo como múltiplos bursts, ou seja, dados que apresentam mais de um burst).

Tanto as irregularidades no vozeamento de fricativas, quanto a interrupção de vozeamento nas oclusivas foram renomeadas, em nossos dados, como bloqueios orais, uma vez que essa é a irregularidade presente nos dois tipos de segmentos. Observe, nas setas da Figura 8 (a e b), que há um clareamento nos dois espectrogramas na região de produção das consoantes oclusiva e fricativa. Esse clareamento configura um bloqueio do trato oral. Note também que, na Figura 8 (c), ocorrem várias explosões acústicas. Desse modo, todas as oclusivas que apresentaram mais de uma explosão na liberação da oclusão oral foram renomeadas como apresentando múltiplos bursts.

(a)
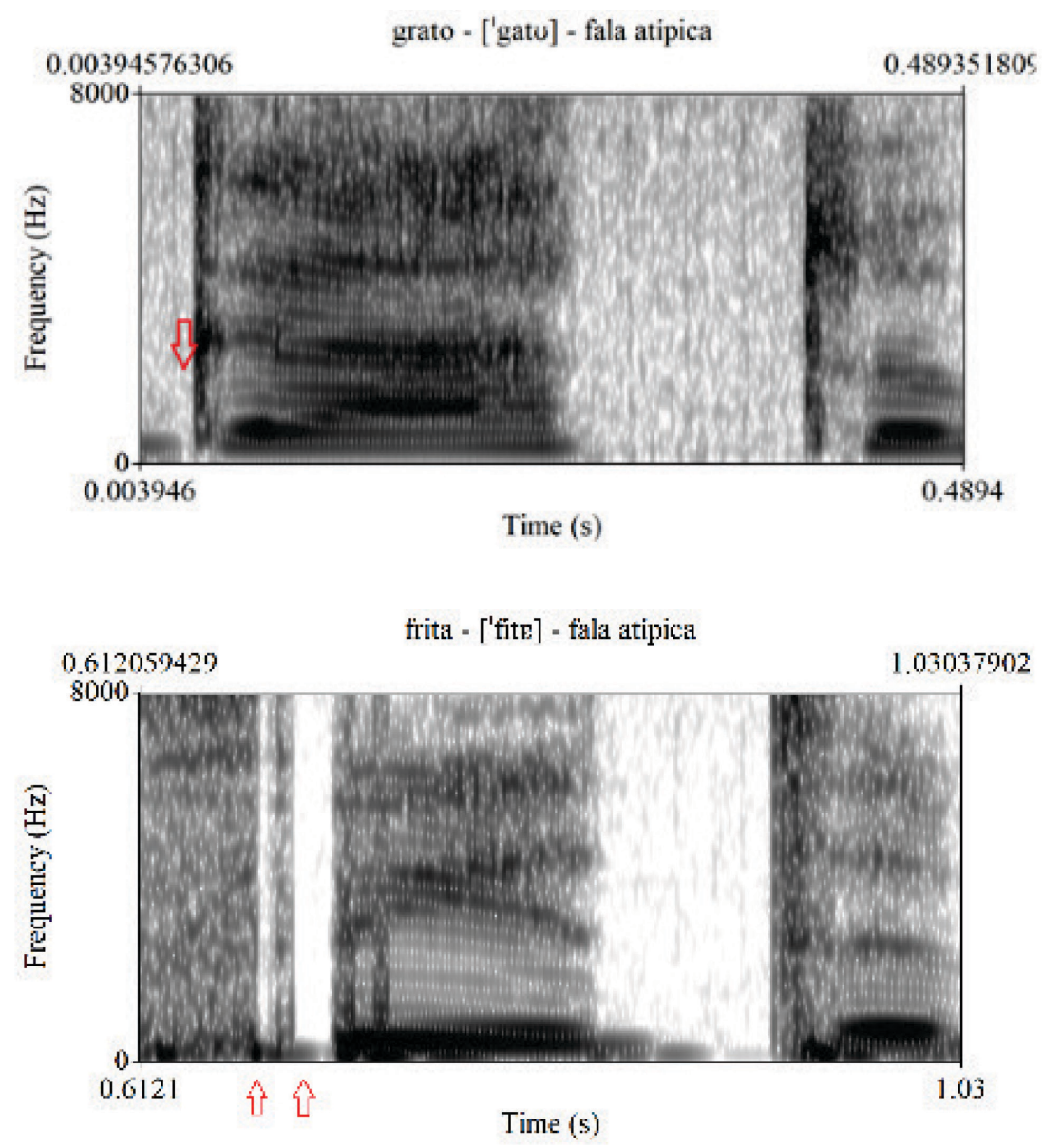

\footnotetext{
${ }^{21}$ Como o número de dados aqui tratados não nos permite muitas classificações, vamos agrupar certas especificidades apresentadas por Cristofolini (2013). Essas especificidades acústicas apresentam características que permitem o seu agrupamento e, por essa razão, vamos renomeá-las.
}

${ }^{22}$ Tanto as irregularidades no vozeamento de fricativas, quanto a interrupção de vozeamento, caracterizam-se em nossos dados como bloqueios orais. 


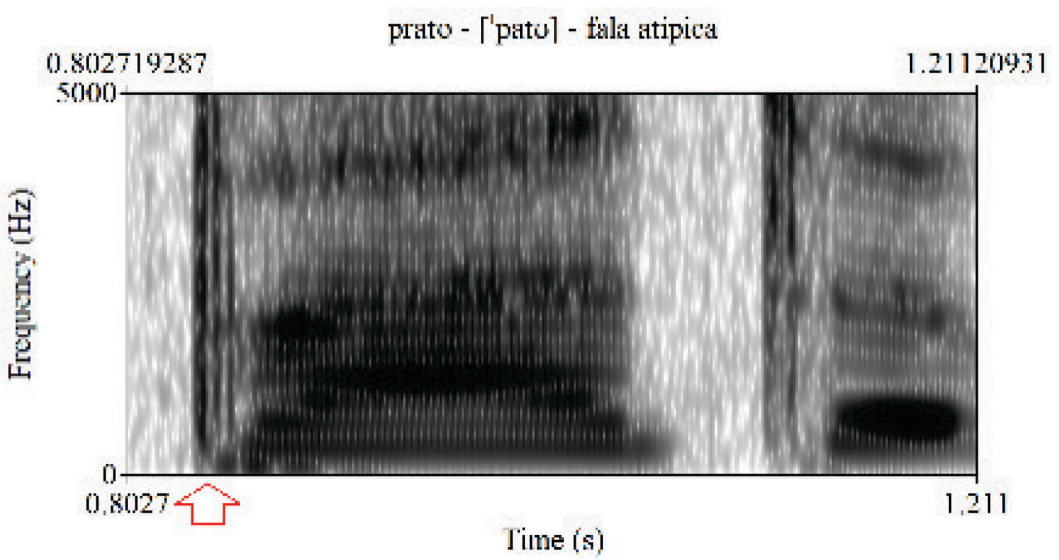

Figura 8: Espectrogramas das palavras (a) grato, (b) frita e (c) prato em fala atípica com os eventos: bloqueios orais e múltiplos bursts Fonte: elaboração dos autores

Assim, na Figura 8, podemos observar exemplos do evento bloqueios orais, nas setas vermelhas, em (a), em uma oclusiva vozeada [g] e, em (b), em uma fricativa não-vozeada [f]; e um exemplo do evento múltiplos bursts, na seta vermelha em (c), em uma oclusiva nãovozeada [p]. Observe agora os percentuais de ocorrência desses eventos acústicos na Tabela 7:

\begin{tabular}{|c|c|c|c|c|}
\hline \multicolumn{2}{|c|}{ Eventos acústicos ${ }^{23}$} & Fala típica & Fala Atípica & Total \\
\hline \multirow{2}{*}{ Bloqueio Oral } & $\mathrm{CCV}$ & $15(12 \%)$ & $26(21 \%)$ & $41(33 \%)$ \\
\hline & $\mathrm{CV}$ & $14(11 \%)$ & $17(14 \%)$ & $31(25 \%)$ \\
\hline \multirow{2}{*}{ Múltiplos bursts } & $\mathrm{CCV}$ & $3(2 \%)$ & $25(20 \%)$ & $28(22 \%)$ \\
\hline & $\mathrm{CV}$ & $8(6 \%)$ & $17(14 \%)$ & $25(20 \%)$ \\
\hline \multicolumn{2}{|c|}{ Total } & $40(32 \%)$ & $85(68 \%)$ & $125(100 \%)$ \\
\hline
\end{tabular}

Tabela 7: Eventos acústicos predominantes nos dados investigados

Fonte: elaboração dos autores

Na Tabela 7, estão sumarizados os resultados referentes aos dois eventos acústicos mais recorrentes nas falas infantis que estão relacionados às oclusivas e fricativas. São eles: o bloqueio oral e múltiplos bursts. Pela Tabela 7, podemos notar que as crianças com desvios fonológicos apresentam um percentual muito maior desses eventos, quando comparadas às produções de crianças com fala típica, tanto em sílabas CCV quanto em sílabas CV. Em sílabas CCV, verificamos que 29,21\% dos dados produzidos por crianças com fala atípica apresentaram bloqueios orais e 28,09\% dos dados exibiram múltiplos bursts, contra 17,86\% e 3,57\% produzidos por crianças com fala típica, respectivamente. Já em sílabas CV, os dados produzidos por crianças de fala atípica apresentaram 19,10\% tanto de bloqueios orais quanto de múltiplos bursts; enquanto, na fala típica, ocorreram 16,67\% e 9,52\%, respectivamente.

Os dados evidenciam que as crianças com desvio fonológico (fala atípica) apresentam percentuais maiores desses eventos acústicos $\left(X^{2}(3, \mathrm{~N}=125)=8,7 ; p=0,03\right)$, principalmente os relacionados a múltiplos bursts quando comparados com as produções de crianças com fala típica.

\footnotetext{
${ }^{23}$ Lembramos que o número total de dados variou em função de alguns deles apresentarem muito pouca qualidade para as análises acústicas realizadas no presente
} estudo. 
Passemos, na seção a seguir, às respostas as nossas questões de pesquisa.

\section{QUESTÕES DE PESQUISA E CONSIDERAÇÕES FINAIS}

Apresentados os resultados, retomamos nossas questões de pesquisa com a finalidade de tentar respondê-las a partir das discussões apresentadas na seção anterior.

A partir da investigação detalhada da produção do rótico, do vozeamento ou desvozeamento de consoantes vozeadas, da produção da vogal núcleo e da vogal de apoio, e da duração do VOT, respondemos a primeira pergunta sobre o comportamento acústico de sílabas CCV nas produções em fala típica e atípica. Verificamos, então, que crianças com desvio fonológico apresentaram um maior percentual de desvozeamento de consoantes vozeadas se comparadas às produções em fala típica. Também não produziram o rótico em sílabas CCV, no entanto, a duração do VOT e das vogais núcleo dessas sílabas apresentaram-se mais longas.

Considerando-se que, em Vassoler (2016), não foram observadas diferenças significativas entre sílabas CCV em fala típica e atípica, essas características parecem evidenciar que as crianças de fala atípica têm conhecimento fonológico quanto à presença de um segmento que ainda não é produzido por elas.

A segunda questão pretende observar quais diferenças podem ser constatadas, considerando a evolução do refinamento articulatório encontrado nas produções em fala típica e atípica. O detalhamento da análise acústica permitiu perceber que os dois grupos de crianças estão em processo de refinamento articulatório dos gestos envolvidos na produção das sílabas CCV. Embora o ouvinte consiga perceber as sílabas como CCV, crianças com desenvolvimento linguístico típico e com desvio fonológico produzem segmentos com características acústicas inabituais, tais como sons que deveriam ser vozeados, mas são desvozeados, presença de múltiplos bursts (características esperadas em desvios fonológicos) e de bloqueios orais. No entanto, aquelas com desvio fonológico apresentam um maior percentual desses eventos.

Esses resultados parecem confirmar as hipóteses já levantadas por Cristofolini (2013) de que as habilidades motoras orais são aprimoradas até que o gesto articulatório se torne estável. Finalmente, análises de detalhes fonéticos envolvidos na produção de sílabas CCV, como vimos, também fornecem evidências da natureza gradiente dos sons da fala.

\section{AGRADECIMENTOS}

Ao CNPQ, pela bolsa de produtividade em pesquisa (processo 308066/2018-9).

Aos pareceristas anônimos desta Revista, pelos comentários ao texto original que certamente contribuíram para uma versão mais adequada do artigo. Salientamos, no entanto, que as inadequações remanescentes são de nossa inteira responsabilidade.

\section{REFERÊNCIAS}

ARSHAM, H. Kuiper's P-value as a Measuring Tool and Decision Procedure for the Goodness-of-fit Test. Journal of Applied Statistics, v.15, n.3, p.131-135, 1988.

BELANDO, M. G.; LAZZAROTTO-VOLCÃO, C. L.; SEARA, I. C. Estudo acústico experimental da aquisição de onset complexo: dados de uma criança. Veredas Atemática, v.22, n.2, p.149-171, 2018.

BOERSMA, P.; WEENINK, D. Praat v.6.0.19. Disponível em: www.praat.org Acesso em: 14 jun. 2016. 
BRASIL, B. et al. O uso de alongamento compensatório em diferentes gravidades do desvio fonológico. Revista da Sociedade Brasileira de Fonoaudiologia, v. 15, n. 2, p. 231-237, 2010.

CAGLIARI, L. C. Análise fonológica: introdução à teoria e à prática: com especial destaque para o modelo fonêmico. Campinas, SP: Mercado de Letras, 2002.

CLARK, J.; YALLOP, C. An introduction to phonetics and phonology. 2. ed. Cambridge: Blackwell, 1995. p 59 -96.

CEMIN, J.; SEARA, I.C. Caracterização acústica da aquisição ou desenvolvimento do contraste de vozeamento nos plosivos na fala típica e atípica. Letrônica, Porto Alegre, v.10, p. 644-658, 2017.

CEMIN, J. Aquisição do contraste de "vozeamento": um estudo longitudinal. 2014. Tese (Doutorado em Linguística) - Programa de Pós-Graduação em Linguística, Universidade Federal de Santa Catarina, Florianópolis, 2014.

COSTA, L.T. Abordagem dinâmica do rotacismo. 2011. Tese (Doutorado em Linguística) -

Programa de Pós-Graduação em Letras, Universidade Federal do Paraná, Curitiba, 2011.

CRISTÓFARO-SILVA, T.; ALMEIDA, L. On the nature of epenthetic vowels. In: BISOL, L.; BRESCANCINI, C. R; (ed.). Contemporary Phonology in Brazil. Cambridge: Cambridge Scholars Publishing, 2008. p. 193-212.

CRISTOFOLINI, C. Gradiência na fala infantil: caracterização acústica de segmentos plosivos e fricativos e evidências de um período de refinamento articulatório.2013. Tese (Doutorado em Linguística) - Programa de Pós-Graduação em Linguística, Universidade Federal de Santa Catarina, Florianópolis, 2013.

DIAS, R. F. A estratégia de alongamento compensatório e sua relação com habilidades metalinguísticas no desvio fonológico / por Roberta Freitas Dias. - Santa Maria, 2009.

KHARLAMOV, V. Prevoicing and prenasalization in Russian inicial plosives, Journal of Phonetics, n.71, p. 215-228, 2018.

KELLER, E. Fundamentals of Phonetic Sience. In: KELLER, E. (ed.). Fundamentals of speech synthesis and speech recognition. New York: John Wiley \& Sons, 1994. p 5-21.

KLEIN, S. Estudo do V.O.T. no português brasileiro. 1999. Dissertação (Mestrado em Linguística) - Programa de Pós-Graduação em Linguística, Universidade Federal de Santa Catarina, Florianópolis, 1999.

KONG, E. J.; SYRIKA, A.; EDWARDS, J. R. Voiced stop prenasalization in two dialects of Greek. The Journal of the Acoustical Society of America, v.132, n.5, p. 3439-3452, 2012.

MIRANDA, I.C.C.; CRISTÓFARO-SILVA, T. Aquisição de encontros consonantais tautossilábicos: uma abordagem multirrepresentacional. Revista Linguística, v. 7, n.1, p. 1-17, 2011.

NISHIDA, G. A natureza intervocálica do tap no PB. 2009. Dissertação (Mestrado em Letras) - Programa de Pós-Graduação em Letras, Universidade Federal do Paraná, Curitiba, 2009.

OHALA, J. Aerodynamics of phonology. Proceedings of the 4th Seoul International Conference on Linguistics [SICOL], Seoul, p. $92-$ 97, 1997. 
OLIVEIRA, A. M.; BERTI, L. C. Aquisição fonológica típica e atípica do padrão silábico CCV: dados acústicos e articulatórios. Alfa Revista Linguística, v. 62, n. 3, p. 591-612, 2018.

O’SHAUGHNESSY, D. A study of French vowel and consonant durations. Journal of Phonetics, n.9, p.385-406, 1981.

PRESTES, S. P. C. Produção de consoantes oclusivas iniciais do inglês por falantes nativos de PB. 2013. Dissertação (Mestrado) Programa de Pós-Graduação em Letras, Universidade Federal do Paraná, 2013.

R CORE TEAM. R: A language and environment for statistical computing. Vienna, Austria: R Foundation for Statistical Computing. Disponível em: http://www.R-project.org/ Acesso em: 15 jun. 2020.

RAMÍREZ, C. J. Acoustic and perceptual characterization of the epenthetic vowel between the clusters formed by consonant + líquid in Spanish. Selected Proceedings of the 2nd Conference on Laboratory Approaches to Spanish Phonetics and Phonology. In: CAMPOS, M. D. (ed.). Somerville, MA: Cascadilla Proceedings Project, 2006. p.48-61.

SILVA, A. P. Para a descrição fonético-acústica das líquidas no português brasileiro: dados de um informante paulistano. 1996. Dissertação (Mestrado em Linguística) - Instituto de Estudos da Linguagem, Universidade Estadual de Campinas, Campinas, 1996.

SILVA, A. P. As fronteiras entre Fonética e Fonologia e a alofonia dos róticos iniciais em PB: dados de dois informantes do sul do país. 2002. Tese (Doutorado em Linguística) - Instituto de Estudos da Linguagem, Universidade Estadual de Campinas, Campinas, 2002.

SILVEIRA, F. Vogal epentética no português brasileiro: um estudo acústico em encontros consonantais. 2007. Dissertação (Mestrado em Linguística) - Programa de Pós-Graduação em Linguística, Universidade Federal de Santa Catarina, Florianópolis, 2007.

SILVEIRA, F.; SEARA, I. C. Vogal de apoio em grupos consonantais CCV no Português Brasileiro. Revista da ABRALIN, v. 7, n. 1, p. 27-47, 2008.

STEVENS, K. N. Acoustic phonetics. Cambridge, MA: MIT Press, 1998.

VASSOLER, A. M. O. Coordenação gestual na produção de encontros consonantais em crianças com desenvolvimento de linguagem típico e atípico. 2016. Tese (Doutorado em Linguística) - Universidade Estadual de São Paulo, São Paulo, 2016.

\section{()(1) $\circledast$}

Recebido em 18/08/2020. Aceito em 08/10/2020. 